\title{
Septo-optic dysplasia with late-onset seizure: MRI and ophthalmological features
}

Displasia septo-óptica com epilepsia tardia: neuroimagem e alterações oftalmológicas

Julian Letícia FREITAS', Flávio Moura REZENDE FILHO', Leandro Tavares LUCATO², Juliana Maria SALLUM', José Luiz PEDROSO'1, Orlando G. BARSOTTINI ${ }^{1}$

A 31-year-old man presented with tonic-clonic seizures, started at 15-year-old, that improved with carbamazepine. Fundoscopy disclosed small optic discs and arterial tortuosity. Neurological examination and visual acuity were normal. Brain MRI showed hypoplasia of the optic nerves, absence of septum pellucidum and polymicrogyria (Figure 1). Optical coherence tomography showed bilateral retinal nerve fiber layer thinning (Figure 2). Septo-optic dysplasia was diagnosed.

Septo-optic dysplasia is usually reported in children, and is characterized by optic nerve hypoplasia, absent septum pellucidum, cortical malformations and pituitary dysfunction ${ }^{1}$. This patient had no endocrinopathy, and presented with late onset epilepsy, which is unusual in septo-optic dysplasia, ${ }^{1,2}$. The typical MRI changes and optic abnormalities were the clues for the diagnosis ${ }^{2}$.
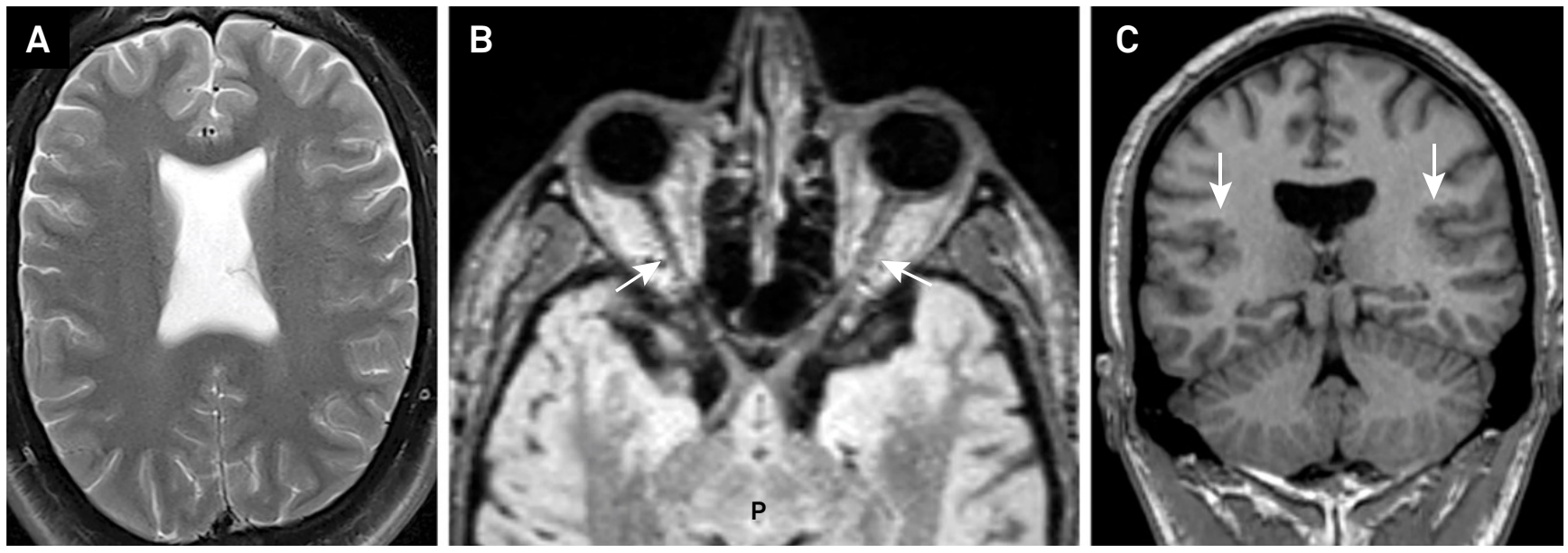

Figure 1. (A) Axial T2-weighted image shows absence of septum pellucidum. (B) Axial FLAIR sequence demonstrates hypoplasia of the optic nerves, more marked on the right (arrows). (C) Coronal T1-weighted image shows absence of septum pellucidum and polymicrogyria in posterior sylvian fissures (arrows).

\footnotetext{
'Universidade Federal de São Paulo, Departamento de Neurologia e Neurocirurgia, São Paulo SP, Brasil;

¿Universidade de São Paulo, Faculdade de Medicina, Hospital das Clínicas, Seção de Neurorradiologia, São Paulo SP, Brasil;

${ }^{3}$ Universidade Federal de São Paulo, Departamento de Oftalmologia, São Paulo SP, Brasil.

José Luiz Pedroso (iD) https://orcid.org/0000-0002-1672-8894

Correspondence: José Luiz Pedroso; Departamento de Neurologia/Ataxias da Escola Paulista de Medicina da UNIFESP; Rua Pedro de Toledo, 650; $04023-062$ São Paulo SP, Brasil; E-mail: jlpedroso.neuro@gmail.com

Conflict of interest: There is no conflict of interest to declare.

Received 14 November 2018; Accepted 26 December 2018.
} 


\section{A}
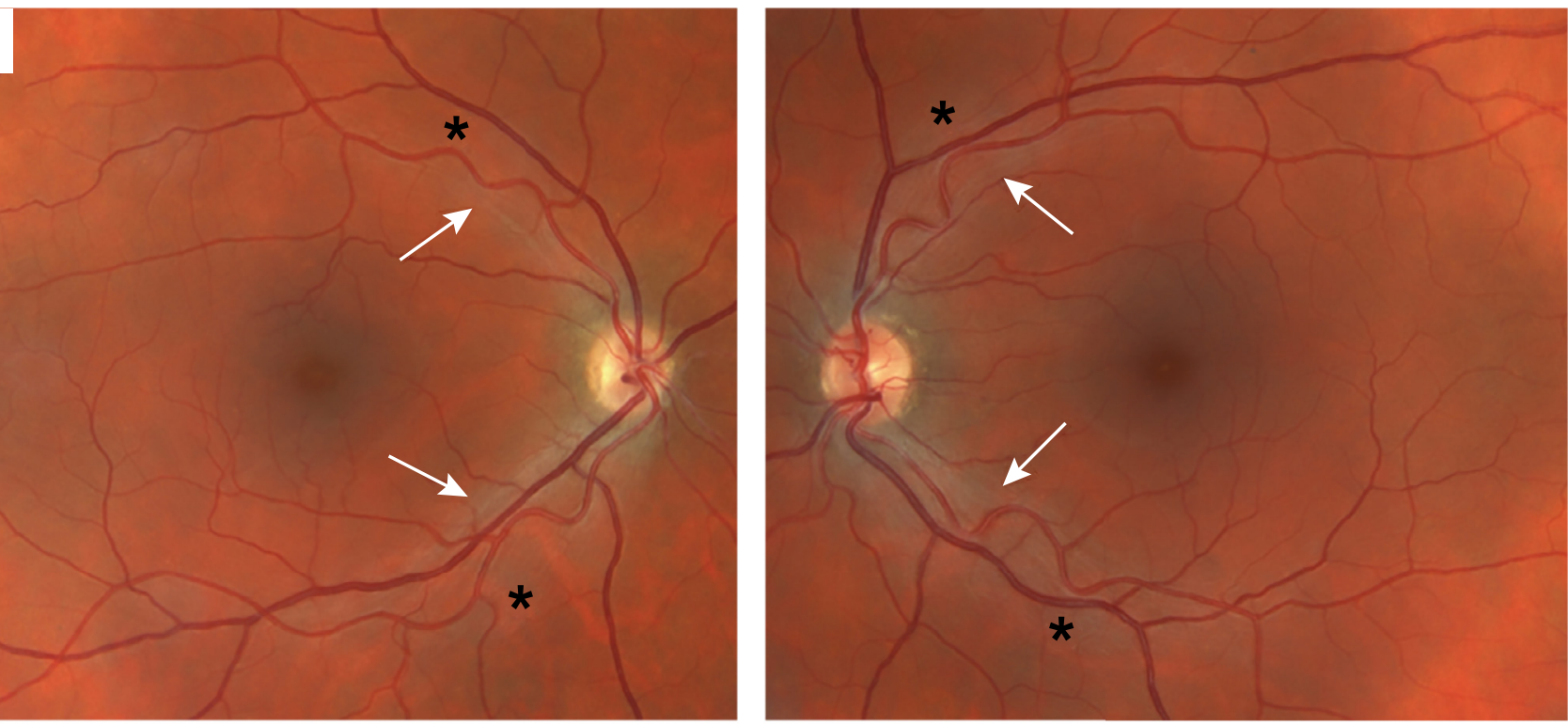

\section{B}

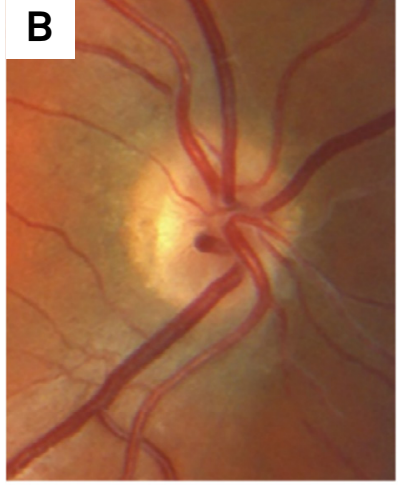

\section{C}

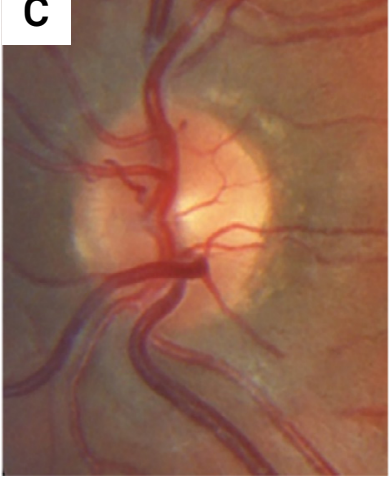

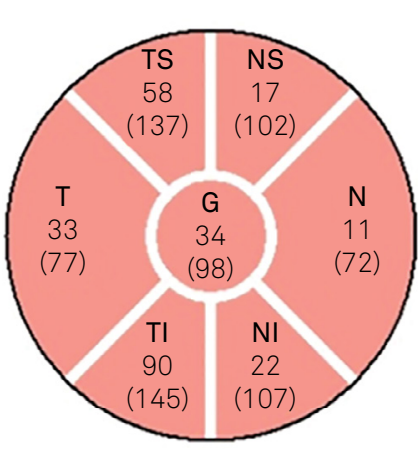

D

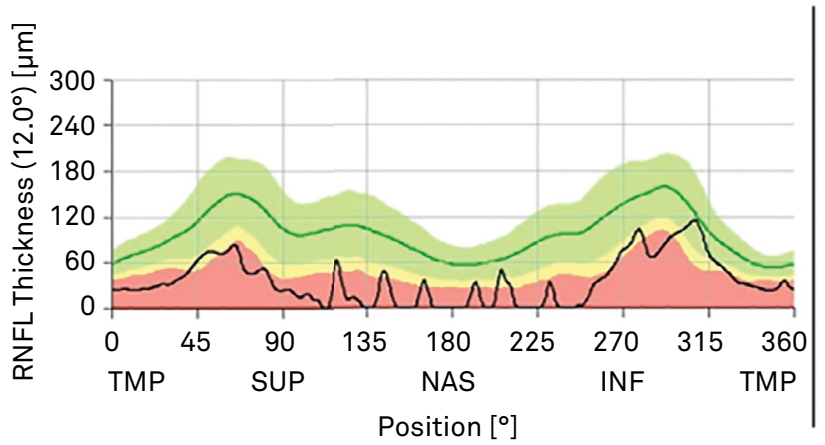

Figure 2. A: Retinography shows hypoplastic optic disc in OD and small disc in OS, arterial tortuosity (asterisks) and reduced visibility of the retinal nerve fibers (arrows) bilaterally. B and C: Absent cup in OD and bilateral temporal pallor. D and E: Thickness maps and graphs show retinal nerve fiber layer thinning in both eyes.

\section{References}

1. Miller SP, Shevell MI, Patenaude Y, Poulin C, O'Gorman AM Septo-optic dysplasia plus: a spectrum of malformations of cortical development. Neurology. 2000;54(8):1701-3. https://doi.org/10.1212/WNL.54.8.1701
2. AlKhateeb M, McLachlan R, Burneo J, Diosy D, Mirsattari S. Six adult patients with septo-optic dysplasia and drug-resistant epilepsy: Clinical findings and course. Epilepsy Behav Case Rep. 2017;8:73-84. https://doi.org/10.1016/j.ebcr.2017.04.001 